\title{
A Research Roadmap for Complementary and Alternative Medicine - What We Need to Know by 2020
}

\author{
Felix Fischer $^{\mathrm{a}} \quad$ George Lewith $^{\mathrm{b}} \quad$ Claudia M. Witt ${ }^{\mathrm{a}, \mathrm{c}} \quad$ Klaus Linde $^{\mathrm{d}} \quad$ Klaus von Ammon $^{\mathrm{e}}$ \\ Francesco Cardini ${ }^{f}$ Torkel Falkenberg ${ }^{g, h}$ Vinjar Fønneb $\varnothing^{i}$ Helle Johannessen ${ }^{\mathrm{j}}$ \\ Bettina Reiter $^{k}$ Bernhard Uehlekel Wolfgang Weidenhammer ${ }^{m}$ Benno Brinkhaus ${ }^{a}$ \\ a Institute for Social Medicine, Epidemiology, and Health Economics, Charité University Medical Center, Berlin, Germany \\ ${ }^{\mathrm{b}}$ Complementary and Integrated Medicine Research Unit, University of Southampton, UK \\ ${ }^{c}$ Center for Integrative Medicine, School of Medicine, University of Maryland, Baltimore, MD, USA \\ d Institute of General Practice, Klinikum rechts der Isar, Technische Universität München, Munich, Germany \\ e Institute of Complementary Medicine (KIKOM), University of Bern, Switzerland \\ ${ }^{f}$ Healthcare and Social Agency of Emilia Romagna Region, Bologna, Italy \\ ${ }^{g}$ Research Unit for Integrative Healthcare Research, Karolinska Institute, Stockholm, \\ ${ }^{\text {h }}$ IC - The Integrative Care Science Center, Järna, Sweden \\ National Research Center on Complementary and Alternative Medicine (NAFKAM), University of Troms $\varnothing$, Norway \\ j Institute of Public Health, Research Unit Health, Man and Society, University of Southern Denmark, Odense, Denmark \\ k International Academy for Holistic Medicine, Vienna, Austria \\ I Institute of Complementary Medicine, Department of Internal Medicine, University Hospital Zurich, Switzerland \\ ${ }^{m}$ Competence Centre for Complementary Medicine and Naturopathy, Klinikum rechts der Isar, Technische Universität München, \\ Munich, Germany
}

\section{Keywords}

Clinical research - Epidemiological research .

Research methodology .

Complementary and alternative medicine .

Consensus process $\cdot$ Research priorities

\section{Summary}

Background: The CAMbrella coordination action was funded within the Framework Programme 7. Its aim is to provide a research roadmap for clinical and epidemiological research for complementary and alternative medicine (CAM) that is appropriate for the health needs of European citizens and acceptable to their national research institutes and healthcare providers in both public

A short version of work package 7 work and results including the CAMbrella research roadmap has been published recently in Fischer HF, Lewith G, Witt CM, Linde K, von Ammon K, Cardini F, Falkenberg T, Fønnebø V, Johannessen H, Reiter B, Uehleke B, Weidenhammer W, Brinkhaus B: High prevalence but limited evidence in complementary and alternative medicine: guidelines for future research. BMC Complement Altern Med 2014;14:46. and private sectors. One major issue in the European research agenda is the demographic change and its impact on health care. Our vision for 2020 is that there is an evidence base that enables European citizens to make informed decisions about CAM, both positive and negative. This roadmap proposes a strategic research agenda for the field of CAM designed to address future European health care challenges. This roadmap is based on the results of CAMbrella's several work packages, literature reviews and expert discussions including a consensus meeting. Methods: We first conducted a systematic literature review on key issues in clinical and epidemiological research in CAM to identify the general concepts, methods and the strengths and weaknesses of current CAM research. These findings were discussed in a workshop (Castellaro, Italy, September 7-9th 2011) with international CAM experts and strategic and methodological recommendations were defined in order to improve the rigor and relevance of CAM research. These recommendations provide the basis for the research roadmap, which was subsequently discussed in a consensus conference (Järna, Sweden, May 9-11th 2012) with all CAMbrella members and the CAMbrella advi-

\section{KARGER}

Fax +497614520714

Information@Karger.com

www.karger.com (c) 2014 S. Karger GmbH, Freiburg

$1661-4119 / 14 / 0212-\cdots \bullet \bullet \$ 39.50 / 0$

Accessible online at:

www.karger.com/fok
Felix Fischer, $\mathrm{PhD}$

Institute for Social Medicine, Epidemiology and Health Economics

Charité - University Medical Center

Luisenstraße 57, 10098 Berlin, Germany

felix.fischer@charite.de 
sory board. The roadmap was revised after this discussion in CAMbrella Work Package (WP) 7 and finally approved by CAMbrella's scientific steering committee on September 26th 2012. Results: Our main findings show that CAM is very heterogenous in terms of definitions and legal regulations between the European countries. In addition, citizens' needs and attitudes towards CAM as well as the use and provision of CAM differ significantly between countries. In terms of research methodology, there was consensus that CAM researchers should make use of all the commonly accepted scientific research methods and employ those with utmost diligence combined in a mixed methods framework. Conclusions: We propose 6 core areas of research that should be investigated to achieve a robust knowledge base and to allow stakeholders to make informed decisions. These are:

Research into the prevalence of CAM in Europe: Reviews show that we do not know enough about the circumstances in which CAM is used by Europeans. To enable a common European strategic approach, a clear picture of current use is of the utmost importance.

Research into differences regarding citizens' attitudes and needs towards CAM: Citizens are the driver for CAM utilization. Their needs and views on CAM are a key priority, and their interests must be investigated and addressed in future CAM research.

Research into safety of CAM: Safety is a key issue for European citizens. CAM is considered safe, but reliable data is scarce although urgently needed in order to assess the risk and cost-benefit ratio of CAM.

Research into the comparative effectiveness of CAM: Everybody needs to know in what situation CAM is a reasonable choice. Therefore, we recommend a clear emphasis on concurrent evaluation of the overall effectiveness of CAM as an additional or alternative treatment strategy in real-world settings.

Research into effects of context and meaning: The impact of effects of context and meaning on the outcome of CAM treatments must be investigated; it is likely that they are significant.

Research into different models of CAM health care integration: There are different models of CAM being integrated into conventional medicine throughout Europe, each with their respective strengths and limitations. These models should be described and concurrently evaluated; innovative models of CAM provision in health care systems should be one focus for CAM research.

We also propose a methodological framework for CAM research. We consider that a framework of mixed methodological approaches is likely to yield the most useful information. In this model, all available research strategies including comparative effectiveness research utilis- ing quantitative and qualitative methods should be considered to enable us to secure the greatest density of knowledge possible. Stakeholders, such as citizens, patients and providers, should be involved in every stage of developing the specific and relevant research questions, study design and the assurance of real-world relevance for the research. Furthermore, structural and sufficient financial support for research into CAM is needed to strengthen CAM research capacity if we wish to understand why it remains so popular within the EU. In order to consider employing CAM as part of the solution to the health care, health creation and self-care challenges we face by 2020 , it is vital to obtain a robust picture of CAM use and reliable information about its cost, safety and effectiveness in real-world settings. We need to consider the availability, accessibility and affordability of CAM. We need to engage in research excellence and utilise comparative effectiveness approaches and mixed methods to obtain this data. Our recommendations are both strategic and methodological. They are presented for the consideration of researchers and funders while being designed to answer the important and implicit questions posed by EU citizens currently using CAM in apparently increasing numbers. We propose that the EU actively supports an EUwide strategic approach that facilitates the development of CAM research. This could be achieved in the first instance through funding a European CAM coordinating research office dedicated to foster systematic communication between EU governments, public, charitable and industry funders as well as researchers, citizens and other stakeholders. The aim of this office would be to coordinate research strategy developments and research funding opportunities, as well as to document and disseminate international research activities in this field. With the aim to develop sustainability as second step, a European Centre for CAM should be established that takes over the monitoring and further development of a coordinated research strategy for CAM, as well as it should have funds that can be awarded to foster high quality and robust independent research with a focus on citizens health needs and pan-European collaboration. We wish to establish a solid funding for CAM research to adequately inform health care and health creation decision-making throughout the EU. This centre would ensure that our vision of a common, strategic and scientifically rigorous approach to CAM research becomes our legacy and Europe's reality. We are confident that our recommendations will serve these essential goals for EU citizens. 


\section{Schlüsselwörter}

Klinische Forschung · Epidemiologische Forschung .

Forschungsmethodik .

Komplementäre und alternative Medizin .

Konsensusprozess · Forschungsprioritäten

\section{Zusammenfassung}

Hintergrund: CAMbrella wurde als Koordinierungsprojekt im Rahmen des 7. Rahmenprogramms für Forschung und technologische Entwicklung der Europäischen Kommission gefördert. Aufgabe des Projekts war es, eine "Roadmap» für künftige klinische und epidemiologische Forschung auf dem Feld der Komplementär- und Alternativmedizin (CAM) zu entwickeln, die den Bedürfnissen der Bevölkerung Europas Rechnung trägt und sowohl nationalen Forschungseinrichtungen als auch privaten und öffentlichen Anbietern von Gesundheitsdienstleistungen entgegenkommt. Eine der großen Herausforderungen für die Wissenschaft in Europa ist der demografische Wandel und seine Folgen für die Gesundheitssysteme. Unser Ziel für das Jahr 2020 ist es, eine Wissensbasis zu schaffen, die es den Bürgern Europas ermöglicht, informierte Entscheidungen hinsichtlich komplementär- und alternativmedizinischer Verfahren zu treffen. Mit dieser Roadmap schlagen wir eine Forschungsstrategie vor, die diesen zukünftigen Herausforderungen gerecht wird. Diese Strategie beruht auf den Ergebnissen der einzelnen Arbeitsgruppen des CAMbrella-Projekts, systematischen Literaturübersichten und Expertendiskussionen einschließlich einer Konsensuskonferenz. Methoden: Als erster Schritt wurde ein systematischer Literaturüberblick erarbeitet, in dem allgemeine Konzepte, Methoden sowie Stärken und Schwächen der bisherigen komplementärmedizinischen Forschung identifiziert wurden. Die hieraus gewonnenen zentralen Ergebnisse wurden mit international renommierten Experten im Rahmen eines Workshops (Castellaro, Italien, 7.-9. September 2011) diskutiert und Empfehlungen erarbeitet, die die Qualität und Relevanz von komplementärmedizinischer Forschung erhöhen sollen. Diese Empfehlungen stellen die Basis der hier vorgeschlagenen Forschungsstrategie dar, die in der Folge im Rahmen einer Konsensuskonferenz (Järna, Schweden, 9.-11. Mai 2012) mit allen Mitgliedern des CAMbrella-Konsortiums einschließlich des Beirates abgestimmt wurde. Die Roadmap wurde in der Folge im CAMbrella Work Package (WP) 7 überarbeitet und schließlich durch CAMbrellas Leitungsgremium am 26. September 2012 freigegeben. Ergebnisse: Sowohl Definition als auch rechtlicher Status von CAM-Verfahren unterscheiden sich stark zwischen den Ländern Europas. Dies gilt auch für die Bedürfnisse und Einstellungen der in Europa lebenden Menschen bezüglich dieser
Verfahren. Es ist Konsens, dass CAM-Verfahren im Rahmen der bekannten und akzeptierten wissenschaftlichen Forschungsmethoden erforscht und dabei verschiedene Forschungsperspektiven berücksichtigt werden sollen. Schlussfolgerungen: Wir schlagen 6 zentrale Forschungsgebiete vor. Diese erscheinen uns als maßgeblich für den Aufbau einer Wissensbasis zur Förderung informierter Entscheidungen. Diese sind:

Prävalenz: Bisher gibt es zu wenige Daten über die Situationen, in denen CAM in Europa genutzt und eingesetzt wird. Um die Umsetzung einer europaweiten Forschungsstrategie zu ermöglichen, muss die Datenlage über die Nutzung von CAM dringend verbessert werden.

Einstellungen und Bedürfnisse: Die Bürger Europas sind der Hauptmotor für den Einsatz von CAM. Ihre Bedürfnisse und Einstellungen spielen eine entscheidende Rolle und müssen daher erforscht und berücksichtigt werden.

Sicherheit: Die Sicherheit komplementär- und alternativmedizinischer Verfahren ist ein Kernanliegen. CAM wird zwar häufig als sicher angesehen, aber für eine Bewertung des Verhältnisses von Kosten und Nutzen muss die Datenlage verbessert werden.

Wirksamkeit: Jeder sollte wissen können, ob und wann komplementär- und alternativmedizinische Verfahren eine vernünftige Wahl sind. Darum empfehlen wir einen klaren Fokus auf klinische Studien des Behandlungsalltags, die den Gesamtnutzen komplementär- und alternativmedizinischer Verfahren als zusätzliche oder alternative Behandlungsmethode erforschen.

Kontext: Der Einfluss von Kontexteffekten wie Erwartungen muss weiter erforscht werden; wir halten sie für bedeutsam.

Modelle der Integration: Die verschiedenen Modelle der Einbindung von CAM in die Gesundheitssysteme mit ihren spezifischen Stärken und Schwächen sollten zunächst beschrieben und evaluiert werden. Weiterhin sollten neue, innovative Ansätze der Integration erforscht werden.

Unser Vorschlag bezieht sich auch auf einen methodischen Rahmen. Das Höchstmaß an Wissen wird unserer Meinung nach mit einem "mixed methods»-Ansatz erreicht, in dem zur Beantwortung der Forschungsfrage unterschiedliche Methoden kombiniert werden. Stakeholder wie z.B. Bürger, Patienten und CAM-Anbieter sollten in allen Phasen der Studienplanung involviert werden, um die Relevanz der Forschungsfrage und Durchführbarkeit der Studie zu verbessern. Außerdem muss es eine strukturelle und ausreichende Förderung solcher Forschung geben, sowohl auf Projektebene als auch als Förderung einzelner Wissenschaftler. Eine solche Stärkung der wissenschaftlichen Infrastruktur ist notwendig, wenn wir verstehen wollen, warum CAM so populär in Europa ist. 
Damit CAM einen Teil zur Lösung von Herausforderungen im Bereich Gesundheit leisten kann, mit denen wir bis zum Jahr 2020 konfrontiert sein werden, ist ein genauer Überblick über die Häufigkeit der Nutzung ebenso notwendig wie valide Informationen zu Wirksamkeit, Sicherheit und Kosten. Die Verfügbarkeit, Erreichbarkeit und Bezahlbarkeit von CAM muss berücksichtigt werden. Wissenschaftliche Exzellenz muss gefördert werden. Unsere Empfehlungen sind sowohl strategischer als auch methodologischer Natur. Sie sollen sowohl von Forschern als auch Förderern berücksichtigt werden und wurden entwickelt, um die wichtigen Fragen von EU-Bürgern zu beantworten, unter denen die Anzahl der CAMNutzer weiter steigt. Die EU sollte eine europaweite Forschungsstrategie unterstützen und könnte das zunächst durch die Gründung eines Europäischen CAM-Koordinierungsbüros erreichen, das die Kommunikation zwischen Regierungen, öffentlichen und privaten Forschungsför-

\section{Preface}

The use of complementary and alternative medicine (CAM) including practices such as acupuncture, anthroposophic medicine, aromatherapy, herbal medicine, homeopathy, kinesiology, massage, naturopathy, shiatsu, and yoga has increased in Western industrialised nations over the last 25 years [1-3]. The WHO Global Atlas of Traditional, Complementary and Alternative Medicine [4] concludes that CAM is highly prevalent within Europe. However, the report was unable to arrive at a clear picture of CAM use across the whole EU as the only reliable evidence available came from just a few EU member states. Furthermore, there has been little interest from the pharmaceutical industry or national publicly funded research organizations within the EU in understanding more about this field. Consequently, European research in the field of CAM is limited and our knowledge about CAM is very poor; for instance in the UK $0.0085 \%$ of national medical research funds are spent on CAM research while over $10 \%$ of the UK population uses CAM each year and approximately $50 \%$ are lifetime users [5]. In contrast, in the USA CAM research has been well funded over the last 2 decades with more than USD 120 Million annually through National Institutes of Health $(\mathrm{NIH})$ funds from the National Center for Complementary and Alternative Medicine (NCCAM; www.nccam.nih.gov).

There is considerable heterogeneity within CAM in the EU; this encompasses the terms, definitions, legislation, and providers of CAM. Physicians and non-medical providers provide CAM in a variety of settings. These differences have hampered the development of a pan-European strategy for CAM research in the past.

There are major health care challenges in all European countries as the demographics change. CAM is frequently em- derern, Wissenschaftlern und Bürgern fördert. Ein Ziel dieser Institution könnte sein, strategische Entwicklungen und Forschungsfördermöglichkeiten zu koordinieren, zu dokumentieren und zu verbreiten. Als zweiter Schritt könnte ein European Centre for CAM gegründet werden, dass die Umsetzung und Weiterentwicklung einer europäischen Forschungsstrategie verfolgt. Dieses Zentrum sollte über Mittel verfügen, um besonders relevante Forschung, die ihr Augenmerk auf die Bedürfnisse der Bürger richtet, in länderübergreifenden Projekten zu fördern. Wir halten eine solche solide Finanzierungsgrundlage für unerlässlich, um individuelle und politische Entscheidungsprozesse hinsichtlich CAM unterstützen zu können. Eine solche Institution könnte sicherstellen, dass eine europäische strategisch ausgerichtete und wissenschaftlich belastbare CAM-Forschung auf der Basis der unterbreiteten Vorschläge umgesetzt werden kann.

ployed in the management of chronic long-term conditions, health promotion and illness prevention, so evidence-based practice is vital to future health planning. This research roadmap describes a strategic approach to CAM research for the period 2012-2020 and beyond. The overall aim is to provide the EU and its citizens with more valuable scientific information to enable them to build the evidence for thoughtful stakeholder decisions about CAM treatments. This roadmap deals with both epidemiological and clinical research and suggests the implementation of appropriate research methods. It is important to mention that although basic research is an important field within CAM, it was excluded a priori from CAMbrella as part of this roadmap.

This document was approved by the CAMbrella group on September 26th 2012, representing members from the following European countries: Austria, Denmark, France, Germany, Hungary, Italy, Norway, Romania, Spain, Sweden, Switzerland, and UK. The CAMbrella Scientific Steering Committee approved the final version of this CAM research roadmap.

\section{Introduction}

The increasing prevalence of antibiotic resistance, mental health disorders and various chronic diseases are just some examples of health issues which will become even more relevant in the very near future for Europe. Europe will go through major demographic changes with an increasing elderly population. Obviously, such an increase challenges almost every aspect of our society, but this is especially true in the field of health care. With an older population we will most certainly need to deal with an increase in multi-morbidity involving a range of chronic diseases, such as arthritis, cardiovascular dis- 
eases, chronic obstructive pulmonary disease (COPD), diabetes and some cancers. This will challenge the scientific, personal and financial facilities of every health care system in Europe. A strategy that allows us to manage these changes is needed in order to serve the needs of European citizens.

\section{CAM}

European citizens use CAM for treatment of chronic conditions, but also for health maintenance, health literacy, self-empowerment and self-care and illness prevention. Large numbers of European citizens are using CAM; approximately $40 \%$ of patients with some common cancers, such as breast and prostate cancer, seek CAM during their courses of illness. Based on surveys in both the UK and Germany it would appear that between $10 \%$ and more than $50 \%$ of the population use CAM each year. These demographics call for a structured and thoughtful investment in CAM research to provide our EU citizens with evidence they need to make clear decisions about their CAM use.

The drivers for CAM use are many and varied. Individual choice is undoubtedly an important trigger for CAM use. Citizens appear to make this choice because they claim that there are fewer side effects when using CAM and these treatments are considered to be safe and natural. This assumption needs to be investigated and challenged. CAM users often express the view that these approaches fit their enablement/empowerment process because they can actively participate in the process of healing or coping with their illness.

In a changing society, where people want to have more control over their health and health treatments and where the numbers of multimorbid patients are increasing, these diverse drivers for CAM use are likely to become more relevant.

CAM has been defined in various ways over decades in different parts of the world. In order to develop a pan-European relevant definition of CAM, the authoritative World Health Organization (WHO) definition of CAM was slightly revised to accommodate European traditional medicine systems and the fact that some systems and modalities may be used today within conventional health care:

'Complementary and Alternative Medicine (CAM) utilised by European citizens represents a variety of different medical systems and therapies based on the knowledge, skills and practices derived from theories, philosophies and experiences used to maintain and improve health, as well as to prevent, diagnose, relieve or treat physical and mental illnesses. CAM has been mainly used outside conventional health care, but in some countries certain treatments are being adopted or adapted by conventional health care.' (CAMbrella Work Package 1).

\section{$C A M$ within the $E U$}

There have been some efforts by the European Union to gather knowledge in the field of CAM, e.g., the 'COST B4' project on unconventional medicine in Europe (1993-1995) and the 'Concerted Action for Complementary and Alterna- tive Medicine Assessment in the Cancer Field' (2002-2005). CAMbrella is within the 7th Framework Programme, and the EU simultaneously funded research into traditional Chinese medicine (TCM) (GP-TCM, TCM-Cancer, TCM-VASC), Tibetan medicine (TIBETAN) and African traditional health (MUTHI, BRIDGING GAPS).

In contrast to the recent research programmes, the main aspect of the current research programmes is a shift towards a more general and common strategic approach to important and relevant issues within Europe. One of the major issues is the demographic change and its impact on health care. For example, on November 9th 2011, the EU commission adopted a legislative proposal for the 3rd multi-annual programme Health for Growth (2014-2020). It focuses on 4 specific objectives:

- To address shortages of resources and to facilitate uptake of innovation in health care in order to contribute to innovative and sustainable health systems.

- To increase access to medical expertise, health care quality and patient safety in order to generally improve health care for EU citizens.

- To address the key risk factors by best-practice prevention, in order to prevent diseases and promote good health.

- To develop common approaches for health emergencies. Similarly, the European Innovation Partnership on Active and Healthy Ageing has been established recently. The programme is oriented towards its headline target by 2020: increasing the number of healthy life years (HLYs) by 2 in the EU on average. The main objectives are:

- To address prevention, early diagnosis, screening and treatment of ageing-related chronic diseases, such as Alzheimer's disease, diabetes, cancer or Parkinson's disease.

- To develop a more integrated approach to care delivery to improve cost-effectiveness and sustainability of health systems.

- To enable older people for a more independent and active life.

CAM is already seen by many patients as a treatment strategy for chronic diseases, disease prevention and health management; it would therefore seem particularly relevant to the 2 EU programmes mentioned above. CAM appears to enable self-care and the co-creation of individual health - issues that we wish to understand and investigate further. This roadmap will build the foundations for a common European research approach for CAM research.

\section{CAMbrella and Its Aims}

Established under the 7th Framework Programme, CAMbrella is a coordination action aiming to foster a network for EU CAM research. CAMbrella was funded to provide an overview of various aspects of CAM within the EU, to identify the needs of the various stakeholders in this field and to analyse how this information might best be delivered in a thoughtful and pragmatic manner. One objective of this project is to de- 
velop a roadmap for future European research in CAM that is appropriate for the health needs of European citizens and acceptable to their public and private national research institutes and health care providers. In order to achieve this, major EUbased CAM research groups were identified and brought together to allow the development of a structured and cooperative collaboration. CAMbrella aimed to identify the major international research stakeholders and seek their advice and cooperation as well as to link to stakeholders representing CAM users, medical and non-medical providers and producers.

Prior to the project, a number of requirements were identified, which are crucial to enable meaningful and reliable comparisons within Europe in this neglected health care domain. These requirements include the need for definitions for CAM and a clearer picture of CAM in the various European countries with respect to the expectations and requirements of the populations seeking CAM treatment. The specific aims of CAMbrella and the associated work packages (WP) can be summarised as to

- develop a consensus-based pan-European CAM definition (WP 1);

- review the current legal status of CAM in Europe (WP 2);

- explore the needs and attitudes of the EU citizens with respect to CAM (WP 3);

- evaluate patient demand for CAM and its prevalence in Europe (WP 4);

- explore the providers' perspectives of CAM treatment in Europe (WP 5);

- evaluate the global perspective and strategy for CAM research (WP 6);

- propose an appropriate research roadmap for CAM in the EU (WP 7);

- disseminate and communicate the outcomes of CAMbrella;

- foster a sustainable, high quality collaboration of European CAM researchers (WP 8).

The results from WP 1-6 were fed into the development of the research roadmap. Their key messages are as follows.

WP 1 - terminology: The work package proposes a broad definition of CAM: 'Complementary and Alternative Medicine (CAM) utilised by European citizens represents a variety of different medical systems and therapies based on the knowledge, skills and practices derived from theories, philosophies and experiences used to maintain and improve health, as well as to prevent, diagnose, relieve or treat physical and mental illnesses. CAM has been mainly used outside conventional health care, but in some countries certain treatments are being adopted or adapted by conventional health care.'

WP 2 - regulation: The situation with regard to CAM regulation can be summarised in 3 key points: 1 . There is no common approach to the regulation of CAM practice in Europe. All 39 countries that were studied 'do it their own way.'; 2. Market authorizations of herbal and homeopathic products are regulated similarly in each country in accordance with EU directives; 3. Several EU directives and other legal and informal documents have an indirect but important influence on how patients, practitioners and researchers can relate to CAM in Europe.

Although diversity in health care regulation enables a wider choice of options with regard to CAM in health care, the same diversity seriously hampers any efforts to establish EUwide conditions for both treatment and research.

WP 3 - citizens: Many citizens in Europe have positive attitudes to CAM, and although their attitudes and needs have not been consistently researched across all European countries, some salient and consistent observations emerge: a) Citizens in Europe wish to have access to increased and diverse CAM provision; b) Citizens in Europe need easily accessible and trustworthy information regarding CAM, CAM effectiveness and CAM safety; c) Citizens in Europe require the transparent regulation of CAM products, practitioners and the training of those who practice CAM.

The attitudes and needs of citizens in Europe concerning CAM have been researched in just 18 of 39 European countries; substantial research-based knowledge is primarily available from the UK, while some - but not extensive - knowledge is available from a few other European countries. This suggests that more research in this field is needed.

WP 4 - patients: We are unsure about the exact extent of CAM use within the EU. The data available from the WP4 systematic review is inconclusive and of very variable quality. Many of the studies are of poor methodological quality. There is reliable data in a few countries, but in the majority of the 27 EU states we have no data. A questionnaire-based tool is needed to measure the prevalence of core CAM practices and to obtain reliable population-based data. The existing and piloted questionnaire ICAMQ will require major revision before it can be widely utilised for this purpose.

WP 5 - providers: CAM provision in Europe comprises health care practitioners and physicians with different healing attitudes, medical background, training, certification and practice. Public available data on CAM provision is limited, and scientific publications investigating this field are almost completely lacking. Our main conclusions are: a) CAM provision in Europe requires the transparent harmonisation of CAM training, medical education and certification; b) CAM provision in Europe requires the standards of the regulation and registration bodies for both, therapists and products, to be open to the public; c) CAM provision in Europe appears to have been a neglected field of research. Publically funded research evidence is mainly available from Denmark, Germany, Norway, Switzerland and UK. This suggests that more research is needed in this field throughout the EU and associated countries.

WP 6 - global perspective: From an international perspective including the experience from China, USA, Asia and Australia, it seems that a broad range of mixed methods research strategies should be used to investigate CAM within the EU. 
CAM research strategy for Europe should be based on consensus of the relevant stakeholders, users, providers, researchers and health policy makers; it should be related to national or regional public health needs, disease burden and the prevalence of particular modalities. WP6 suggests the formation of a centralised EU CAM centre with the responsibility to operationalise the CAMbrella recommendations in collaboration with selected EU member states and appropriate (worldwide) CAM academic institutions. This will enable an evidenceinformed health sector reform with appropriate CAM interventions in the EU.

A coordinated research action within the EU will face enormous diversity in the field of CAM and its legal regulation. It must address the lack of comprehensive basic knowledge about attitudes towards CAM as well as its use and provision. It would be wise to learn from international experience.

\section{Work Package 7 of CAMbrella}

The overall aim of CAMbrella WP 7 is to identify consensusbased research strategies for CAM research and to develop a general research map for future clinical and epidemiological research in the field of CAM. In order to describe the challenges that have occurred in CAM research, we analysed the research methods already used for clinical and epidemiological CAM research by conducting a systematic literature review. We also reviewed the research methods used in the studies examined within WP 3, 4 and 5. Finally, we proposed strategies and methods to overcome the shortcomings in prevalence research and research into citizens' needs.

We identified 3,279 references derived from 7 electronic databases and 98 references contributed by CAM experts; 170 papers were included in the analysis. The review [6] concludes that in the scientific community there seems to be a consensus that the research methods used in conventional medicine are applicable to CAM. Randomised controlled trials are useful and applicable methods to evaluate CAM although in some circumstances it might be necessary to adapt these methods pragmatically. Furthermore, most authors are in favour of a broad integration of different research methods (a mixed methods approach), such as those used within comparative effectiveness research (CER) and qualitative studies, to gather real-world evidence about CAM. Major issues described in the literature are the plethora of both general and specific problems experienced within CAM research and some thoughtful and specific suggestions on how to handle those in future research. Interestingly, most problems are related to the design of clinical trials: patient selection, individualised treatments, randomisation and blinding. The probably most important and controversial discussion found in the literature seems to be the question whether efficacy or effectiveness research should be prioritised for future CAM research.

Based on this review, a workshop was held in Castellaro (Italy) September 7-9th 2011, with members of the CAMbrella WP 7, representatives of CAMbrella's advisory board and internationally renowned experts in the field of CAM research. Within this workshop recommendations for further research were developed as the first draft of the roadmap. These recommendations suggest the early involvement of relevant stakeholders when identifying research questions and planning research projects in the field of CAM. They recommend that research should be conducted within a real-world setting to foster evidence for safety and costs as well as to establish knowledge on the range of benefits to users. The most relevant outcomes of CAM treatments need to be identified as well as the public health, health education and clinical situations in which CAM could be appropriate. In addition, use of a broad variety of research methods is recommended, and different types of evidence should be taken into consideration. This includes the need for research training and collaboration with users, providers and other relevant stakeholders. Harmonised prevalence research for EU CAM use is urgently needed and should be one of the first steps toward a broader and more detailed picture of the state of CAM practice in Europe. Safety is a major issue because it is fundamental to the interests of users and providers. Additionally, mechanisms of action are still poorly understood for most CAM modalities. Given the effects experienced by users and providers of CAM, research should include exploration into the nature and impact of those effects. Mixed research methods rather than sole reliance on randomised controlled trials are more likely to provide a broad understanding of CAM, its effects and potential applicability in health care. A Europe-wide approach to research should take advantage of the diversity of CAM throughout Europe and allow comparisons between different models of health system integration with regard to safety, efficacy, effectiveness and the health economic outcomes of CAM treatments.

Based on the results from the literature review and the Castellaro workshop, this roadmap has been developed to establish a strategic guide for future CAM research. We aimed to create a roadmap that is appropriate for the health needs of European citizens and acceptable to their public and private national research institutes and health care providers.

\section{CAM Research Roadmap}

\section{Vision}

Our vision for the year 2020 is that research into CAM will provide a broad but relevant and comprehensive evidence base that enables European citizens and health care providers to come to informed decisions about CAM utilisation for both the individual and society as a whole. We believe that knowledge regarding safety, effectiveness and cost-effectiveness of CAM therapies is crucial to enable those decisions. Furthermore, these decisions need an overall research strategy for CAM that is evidence-based and grounded in clinical practice. We note that CAM is frequently utilised for self-care and per- 
sonal well-being; self-care approaches will become increasingly important strategies by 2020 as we are developing more comorbidities in an ageing European population.

It is our aim to foster robust science that will have a major impact on public health, influencing the quality and quantity of life among the citizens of EU member states. We propose overall research fields of relevance and interest for all stakeholders. We also suggest methodological strategies as to how those fields could be evaluated.

The choice of research areas must be addressed strategically, in cooperation with conventional medical research groups (e.g., primary care, environmental medicine) and with the involvement of stakeholders, such as patients and medical and non-medical CAM providers.

We have identified 6 key research areas, crucial for development of a broad, Europe-wide knowledge base for CAM by 2020:

\section{Research Area 1: CAM Prevalence in the EU}

Goal: A valid descriptive overview of CAM use in Europe.

So far, knowledge about the prevalence of use of CAM in Europe is limited, and little information about CAM prevalence in Europe is available. Data across countries is inconsistent, and it is currently impossible to compare the prevalence of CAM use across all EU member states.

CAMbrella has reviewed the current scientific knowledge about the prevalence of CAM in Europe (see CAMbrella WP 4 report). In our systematic review of CAM prevalence, 5,451 studies were selected in an electronic search out of which 187 papers were identified and analysed reporting the prevalence of CAM use in Europe. The main obstacles in prevalence research were inconsistent or even absent definitions of CAM across the reports and concentration on country-specific CAM modalities. The methodology involved in the available epidemiological studies was generally poor with many studies not piloting their data collection questionnaires and not reporting clearly about their population sample selection and the methods used to obtain a complete and representative sample. CAM use was often measured as a group of therapies rather than individually specified CAM modalities. Finally, because of the heterogeneity of the methods and definitions it was not possible to pool the data in a meta-analysis, and we cannot make a definitive statement of the CAM use in detail in Europe [6].

However, information about what is actually happening in Europe is vital to building a relevant research agenda. The lack of prevalence data is a major obstacle to conducting high quality research because it complicates and obscures the identification of the research fields that are relevant to citizens, providers and purchasers of CAM treatments. Given the diverse European situation with regard to legal regulation of provision and practice (see results of CAMbrella WP 2 report), information about CAM prevalence is essential for health services research, especially the comparison of the health systems across countries. To overcome these problems, and in order to build a more solid foundation for future CAM research, new studies of CAM prevalence should consider the following strategies and suggestions to better enable data pooling and reporting accuracy:

- Identification of a core set of definitions of CAM practices and treatments in order to allow Europe-wide comparison of data. The understanding of what CAM actually is varies to a great extent between European countries. However, these definitions need to take national differences into account.

- Development and agreement on a standardised methodology for surveys is essential for the comparison of the collected data. This methodology should be based on good epidemiological practice, such as the STROBE criteria [7], and should include agreement on the relevant sociodemographic variables of interest.

- Observational studies are generally subject to various biases. Since prevalence of use is a question which only can be answered through observational studies, researchers need to make efforts to manage various forms of bias, especially recall bias. Utilisation of representative samples and encouraging adequate response rates could help to manage self-selection bias and also enhance comparability.

- It would also be important to understand how CAM use differs between specific populations (healthy people and those with chronic illness) as we are aware that CAM is used mainly in addition to conventional care, but that its use is often not disclosed. This is potentially problematic because of interactions with conventional medications [8]; comparative studies between these different populations would be essential.

In conclusion, our suggestion is to develop a standardised approach towards prevalence research throughout Europe.

We recommend: A Europe-wide approach to assess the prevalence of CAM use, practices and modalities using standard definitions.

\section{Research Area 2: Needs and Attitudes of EU Citizens,}

\section{Patients and Providers}

Goal: To increase research-based knowledge about the availability of trustworthy information on CAM, access to CAM and quality of care in CAM for citizens, patients and providers in Europe.

Citizens' attitudes and needs in relation to CAM have only been researched in 18 of the 39 countries in the EU with most of the research in the UK. This means that although some general trends regarding access and quality of care can be identified across countries, this research-based knowledge does not cover the entire European region (see CAMbrella WP 3 report).

A general need for easily accessible and trustworthy information regarding CAM is essential. In some countries, citizens' personal social networks appear to constitute the main source of information about CAM, while biomedical profes- 
sionals seem to constitute an important information source about CAM in other countries. In addition, but to a lesser extent, citizens seem to draw on print and broadcast media for information about CAM. Therefore, research-based knowledge is needed about the validity of different sources of information as the basis for citizens' choice of treatment as well as the safe use and appropriateness of the chosen treatments.

The available research indicates that citizens generally wish to have easy access to CAM. A main obstacle in accessing CAM is that the user pays for treatment out-of-pocket in many countries. The literature points to 2 different attitudes in this regard: In countries where a substantial number of medical doctors provide CAM, citizens and patients seem to prefer that CAM provision be included in public health care. In countries such as UK and Denmark, where CAM is primarily provided by providers without a conventional medical background, citizens appear to be more reluctant to include CAM provision in public health care and seem to enjoy the relative freedom of choice of therapy this service model provides.

There is a need for research that investigates citizens' access to and preferred models of CAM provision in Europe. This should include self-care and over-the-counter (OTC) use of CAM products as well as social and cultural aspects related to citizens' needs and access to CAM for the various different models of CAM provision.

Research designed to help us understand citizens' attitudes and needs concerning the quality of care in CAM provision and use indicates that citizens may value different and distinct aspects of CAM practice to other stakeholders. Issues mentioned in the literature as appealing to users include the provider-patient relationship and the associated greater involvement in one's own care; the individualised whole person approach frequently associated with CAM; and the explanatory frameworks for CAM that are congruent with the citizens' own ideas about health and illness, but may not be evidence-based.

Therefore, research is needed into the relationship between the cultural assumptions underpinning CAM in different countries and their influence on the actual CAM practice within diverse institutional settings. As part of this, it should be investigated whether the treatments include potentially healthpromoting involvement of patients.

Another issue related to the quality of care concerns the qualifications and actual practice of the providers. The educational backgrounds for providers of CAM across and within countries, the forms of CAM and the institutional settings for CAM provision appear to be very heterogeneous as documented in the reports of WP 5 and WP 2. The implications of these findings for the educational qualifications of CAM practitioners have not been investigated in a systematic manner. Thus, identification of the educational background and training of medical and non-medical CAM providers is needed. We need to understand why people decide to become CAM providers in the first place, and we need to understand the impli- cations of current CAM education, training, certification and registration for clinical practice.

The major methodological deficiencies identified in relation to research about citizens' needs and attitudes for CAM are:

- Most of the studies involve low quality reporting and hence uncertainty regarding the quality of the research methodology and the veracity of their results.

- Only few studies focus directly on citizens' needs and attitudes.

- There are a very limited number of articles reporting research regarding citizens' needs and attitudes in most of the EU countries.

These deficiencies call for a strengthening of future research in this area. Citizens' attitudes and needs in relation to CAM deserve to be a priority. We need to obtain comparable and compatible data for all EU countries, so studies should be conducted in parallel in several EU countries where possible. Research approaches suitable for addressing citizens' attitudes and needs include

- large-scale surveys based on validated questionnaires;

- qualitative interview and fieldwork studies with in-depth explorations of locally situated experiences and practice;

- interdisciplinary research, such as mixed methods studies, involving CAM providers and citizens as research partners.

In general, research into citizens' needs and attitudes needs to consider the local, regional and pan-European diversity of citizens (gender, age, ethnicity, social class) and the diversity of CAM provision, providers, practices and modalities.

We recommend: A programme of pan-European research identifying the citizens' accessibility, preferences, reasons for use as well as reported effects and benefits for CAM. This should include the health economics of CAM as well as citizens' and CAM providers' perspectives on education, training and practice of CAM provision. In doing so, attention should be paid to local traditions, ethnic minority groups and other sociocultural factors of relevance.

\section{Research Area 3: CAM Safety}

Goal: Gathering valid information about the safety and the risk/benefit of CAM treatments.

Based on the large number of people seeking CAM treatment and the variability of provided CAM treatments, safety is an issue that must be addressed. Although CAM is considered to be largely safe by funders, citizens and providers, an evidence base for this is essential for all stakeholders.

Safety evaluations of CAM in the past have often focused on self-reports of serious adverse events as well as case reports, without clarifying the quality of treatment, the population denominators and potential causative mechanisms. There are at least 3 different domains, in which safety plays an important role: CAM in the legislative area; the competency and safety of CAM providers and CAM therapies/products; and interactions between CAM and conventional medicine. 
CAM interventions often involve providing more or less complex treatment strategies to people (acupuncture, reflexology and chiropractic). Safety of the people receiving these complex interventions must be secure. CAM treatments are often provided in combination with conventional medicine, e.g., pharmaceuticals. It is not clear if interactions between these treatments may occur which interfere with either the CAM or conventional intervention. Providing CAM treatments must be safe and ethical for all CAM health care professionals including both medical and non-medical practitioners. A clear definition and taxonomy of safety in CAM is needed as prerequisite for valid research into CAM safety. It must take into account the availability of valid information about CAM treatments, treatment providers and the views of citizens on safety of CAM.

The WP 3 literature review showed that citizens evaluate the safety of CAM relative to conventional medical treatment, and often decide that CAM is safer than conventional medical treatment. Although it is known that conventional medical treatment can involve serious risks to the patient's health, and the reported adverse effects of CAM in the research literature are rarely of a serious nature, it is crucial to investigate this area more systematically using scientific comparisons of risks and benefits in different kinds of treatments and reporting and comparing risk/benefit ratios. Future safety evaluations should include information on the provided CAM treatment that was associated with the adverse event (often serendipitous associations, misdiagnosis, mistreatment or insufficient treatment) and the interactions between CAM and conventional medicine.

In principle, 3 different types of safety documentation and research could be considered:

1. Europe- or country-wide CAM surveillance/register systems: Adverse effects associated with CAM should be documented; the most common as well as rare side effects should be covered. Ideally all people receiving CAM should be included, so that proper denominators would be available to clarify potential risk.

2. Clinical trials, observational and comparative effectiveness studies can be utilised to assess the risk of the more common side effects. This allows adequate comparison between benefit and risks of a given treatment compared to a defined control group such as usual care or standard treatment.

3. Single case studies and case histories: Very rare or exceptional adverse effect case histories should be documented and disseminated. Single case studies can be initiated in patients with an increased risk of side effects.

We recommend: Safety is a key issue for European citizens, and clear guidance on CAM safety is needed. A Europe-wide monitoring and registration system for clinical trials, observational and CER studies, single case studies and case histories should be implemented.
Research Area 4: Comparative Effectiveness Research and

\section{Health Economic Evaluation}

Goal: To support clinical and health care policy decisionmaking by evaluating effectiveness and cost effectiveness.

CER has considerable potential to help health care providers as well as patients and clinicians to generate evidence that will facilitate choice among currently available therapeutic options. According to the Institute of Medicine, CER is the generation and synthesis of evidence that compares the benefits and harms of alternative therapeutic methods to prevent, diagnose, treat and monitor a clinical condition or to improve the delivery of care. (Alternative does here not refer to 'alternative medicine', but to 'best care' options). The purpose of CER is to assist consumers, clinicians, purchasers and policy makers to make informed decisions that will improve health care for both the individual and population [9].

'Efficacy' refers to 'the extent to which a specific intervention is beneficial under ideal conditions' [10]. By contrast, 'effectiveness' is a measure of the extent to which an intervention, when deployed in routine circumstances, does what it is intended to do for a specific population [10]. Therefore, effectiveness can often be more important and relevant to policy evaluation and the health care decisions of providers and patients than efficacy. The current movement in conventional medicine towards more CER places strong emphasis on the evaluation of different treatment options by including more heterogeneous patients and by using less standardised treatment protocols and more patient-centred outcomes. However, to date, the majority of clinical trials on CAM have assessed the efficacy rather than the effectiveness. Unfortunately, efforts to achieve methodological purity have often resulted in clinically meaningless and questionable results because patients, interventions and settings were not comparable to the real world; this meant the research outcomes were often not generalisable. CER plays an important role especially for CAM because, as opposed to conventional medicine, CAM is now widely available to the population. As a consequence, a reverse research strategy has been suggested for CAM, with the aim of establishing comparative effectiveness and safety before assessing efficacy of components [11,12].

It is of major interest to ensure that future research on CAM reaches stakeholders to enable them to make informed decisions in real-world situations. CER offers a wide range of research designs [13] and advanced techniques to distil and condense evidence from different types of studies. CER is not limited to randomised trials and includes, among other options, the possibility of using data from observational studies or registries. Pragmatic clinical trials are those randomised trials that are designed explicitly to meet the needs of clinical and policy decision making $[14,15]$. When conducting pragmatic trials, one should take patients' preferences regarding their therapy of choice into account, using either patient preference designs or documentation of patient preferences. Cluster-randomised trials are also a good option that could be used when appropriate. 
Within the framework of CER it is possible to address the most relevant issues regarding CAM in view of the upcoming health care challenges:

- Evaluating CAM as an optional add-on to conventional care as well as an alternative (best care) treatment strategy.

- Addressing medium and long-term effects of CAM in chronic diseases.

- Evaluating the cost/effectiveness ratio of a given CAM treatment compared to a defined control group (e.g., standard care, routine care).

- Involving stakeholders (such as citizens and patients, treatment providers and health care managers/planners, hospital executives and others) in the design of CER studies and ensuring that research focuses on the evidence gaps most relevant to all health care decision makers [16].

Research in a real world-setting is the most promising and relevant approach to identifying the possible contribution of CAM to health care and health creation of European citizens.

We recommend: Future research should emphasize CER in CAM. This will create data that is valuable for all stakeholders and provide useful guidance for future research. Health economic evaluation should be included within CER, and stakeholders should be involved in all relevant stages.

\section{Research Area 5: Meaning and Context Factors in CAM}

Goal: To understand to what extent the clinical effects of CAM treatments are due to meaning and context effects and whether such effects differ from those in conventional medicine.

In most areas of CAM the majority of randomised clinical trials have investigated whether the intervention under test conditions has specific effects over a placebo or sham control intervention. While for a limited number of treatments such as St. John's wort for depression [17], such specific effects have been shown beyond reasonable doubt, many trials have identified only small differences between real and placebo treatments, and these have been of questionable clinical relevance. At the same time there is increasing evidence that patients benefit from a variety of CAM treatments compared to no treatment, usual care alone or in some cases even compared to guideline-based conventional care [18]. This raises some important questions:

- To what extent CAM treatments work through the mechanisms believed to be relevant by their proponents?

- To what extent they work through meaning and context effects?

- Are they associated with stronger meaning or context effects than the conventional treatment option for some conditions or some patients?

These questions are not only of academic relevance. It could be that although a (CAM) therapy is not based on a valid theory or mechanism it may still be the most effective treatment option in a given situation.
Most CAM therapies are considered complex interventions. Treatments sometimes cannot be reduced to a single specific therapeutic ingredient but may also encompass a specific setting as well as diagnostic and interaction processes [19]. Active or maybe only presumably active therapeutic ingredients are embedded in a contextual network. Furthermore we are frequently unsure about the underlying mechanisms of some CAMs so that we may be unable to design an appropriate placebo intervention. Placebo research in the last 2 decades has provided clear evidence that interventions without active ingredients can profoundly influence not only subjective perceptions but also physiological processes [20]. Such effects depend strongly on the meaning and context of an intervention and are mediated by a variety of mechanisms, such as expectation, conditioning and reward. While the concept of complex interventions and experimental evidence from placebo research provides to some extent a theoretical rationale as to why CAM might be associated with strong meaning and context effects empirical, the evidence relevant to clinical practice is limited.

Therefore we see a strong need for research that investigates how and to what extent factors related to patients, providers, patient-provider relationship and interaction as well as to the setting in which CAM treatments are delivered influence patient-relevant outcomes. It is necessary to develop valid and reliable tools to assess components of meaning and context effects to facilitate research and allow for comparisons of results. Special emphasis should be placed on the question of whether CAM includes and provides meaning and context effects within the healing process in a different and broader context than conventional medicine. Such research could lead to a better understanding of the mechanisms of CAM, clarify the value of CAM for use by citizens and patients and help politicians when making reimbursement decisions. Understanding the mechanisms of meaning and contextual effects is also urgently needed to identify the appropriate scope and limits of CAM as well as conventional medical treatments. We are confident that deeper insights into the mechanisms of meaning and context effects will improve treatment in conventional medicine, too.

For most CAM interventions the mechanisms of action are either unknown or only partly understood. Although the basic research on mechanisms of action is not part of this research roadmap it is fundamental to understand that more basic or experimental research is needed also in this field and that this needs to complement the research in meaning or context factors in CAM. Given the importance of context and meaning effects in all medicine, we believe that research into this area should be a priority for medical research in general.

We recommend: Clinical research on CAM treatments should, whenever possible, include components that address aspects relevant to context and meaning effects and attempt to differentiate them from the intrinsic impact of any specific intervention. 


\section{Research Area 6: Models of CAM Integration into the} Health Systems

Goal: To research the different models for integration of CAM into health systems.

There are a plethora of different CAM modalities and treatments, and there is a wide variety of ways in which CAM is provided to European citizens. For example, the legal status and necessary qualifications for CAM provision differ between modalities and within European countries (see CAMbrella WP 2 report). This also affects the costs of CAM for European citizens. CAM is usually provided as an exclusively private service often without any legal regulation, but in some cases there is regulation concerning the qualification of CAM providers and public provision of CAM (see CAMbrella WP 5 report). Some CAM modalities are supported and in some cases there is even reimbursement for CAM treatments provided by medical doctors or CAM practitioners within the public health care system. For example, different approaches of CAM integration have been described as 'opposition', 'integration' and 'pluralism' models [21]. A review of different models of CAM integration and their possible strengths and limitations in Europe is not yet available. CAM provision outside the medical system allows free choice of even 'uncommon' treatments and respects the freedom of European citizens as providers and users of CAM. On the other hand, this could affect safety and might undermine equity of access to treatment. Also, out-of-pocket expenditure for CAM treatments might not be affordable for some people or - in other cases - it might be cheaper than regular health care. Strong legal regulation might lead to the 'underground' provision of CAM without any quality control.

Integration of CAM into the regular health service might enable citizens to access CAM more equitably and build acceptance for CAM, but could also limit the provision of CAM to selected techniques shown to be effective in treatment. This might weaken the possible beneficial effects, such as patient empowerment. These issues are complex and poorly understood. CAM integration into health care is an individual and societal process of change which develops through the behaviours of patients, providers, stakeholders as well as evidence in different contexts of care. The implementation and provision of CAM is a complex matter that should be evaluated in detail as a complex intervention. 'Integration' doesn't mean simply adding a certain amount of 'unconventional' to the 'conventional' of routine care, but developing and testing models of integrated health care tailored to a patient's needs, that include all conventional and CAM approaches that are appropriate. Ideally, an efficient integrative medicine model entails a coordinated, interactive and pragmatic process of change whose main participants are the health service workers and the attending patients.

At this stage there is no consensus as to which model of integration of CAM into the health care system is ideal. To ena- ble decisions about CAM integration into health care, a valid description of the various models of how CAM is integrated is needed. These models should then be concurrently evaluated in order to identify their strengths and limitations.

We recommend: A reliable description and concurrent evaluation of the existing models of CAM provision; the development of innovative models of CAM provision in health care systems should be one focus of CAM research.

\section{Methodological Considerations}

There are some methodological and strategic considerations which must be taken into account when formulating a research agenda in order to foster rigorous research in CAM.

Over the last decade there has been a broad discussion about the utility of different research methods, and we have reviewed some of these important issues separately. We have identified several issues which have constrained the outcome of CAM research in the past, and we propose a methodological framework to overcome these shortcomings.

\section{General Research Framework}

Goal: To enhance the value of research by allowing a broader and more complete assessment of the evidence.

From our point of view, an overall research framework for CAM needs to take the specific characteristics of CAM into account and include these in relation to any research design. Current trends in conventional medicine emphasise the fact that the implications of efficacy studies for clinical practice are overestimated. CER will better inform clinical decisionmaking in usual care, and standards for conducting patientcentred research are currently developed [22].

We particularly favour multi-faceted, mixed method approaches for the evaluation of complex interventions, in which different methods are triangulated to gather the best available information using a non-hierarchical research approach. In quantitative studies, we prefer analyses which go beyond sole reliance on frequent statistics. The results of these statistics, such as effect sizes, numbers of subjects who respond and analyses of individuals, need to be reported, in addition to the commonly accepted presentation of the primary outcomes, to allow for a more inclusive interpretation of results. The conduction of realist reviews [23] and reviews of research methods should allow comprehensive summaries of all types of research from different sources. Such syntheses should be prioritised in areas in which large numbers of individual studies already exist to provide information about best practices and to guide future research.

We recommend: Greater use of mixed methods approaches and more attention to the manner in which research results are transformed into coherent and conclusive reviews. 


\section{Quantitative Research Methods}

Goal: Accounting for complexities in CAM research through the use of quantitative research methods.

A substantial proportion of European populations utilise CAM in order to maintain and create health or treat their illnesses [1,24-26]. In order to enable European citizens, providers, policy makers and other stakeholders to arrive at informed decisions about CAM, they should have a reasonable degree of reliable information regarding

- use of CAM in Europe (see research area 1);

- attitudes towards the modality in question among European citizens (see research area 3 );

- safety of a specific modality or procedure and an understanding of its corresponding risks (see research area 2);

- level of acceptance among a group of providers and funders (see research area 3);

- effectiveness of a CAM modality in clinical practice (see research area 4 );

- its economic sustainability (see research area 4).

In order to gather this information, different types of research (effectiveness, safety, cost-effectiveness, citizens' preferences and satisfaction, health services studies) are needed. Large-scale surveys can help to describe the attitudes of European citizens towards CAM and enable us to understand their knowledge, motivations and preferences with respect to CAM. Observational studies must be conducted to assess safety. Randomised controlled trials in real-world settings are ideal to evaluate the effectiveness of a specific treatment or CAM modality in comparison to existing models of treatment, and concurrent observation of costs allows cost-effectiveness analysis. Different research questions call for different study designs, but these different types of quantitative studies are very relevant to allow us to answer these essential questions about CAM.

CAM modalities were conceived and developed in contexts very different from our present health services and often have a long history. Moreover, the different CAM modalities show different levels of complexity in their provision, varying from the simple prescription of a dietary supplement to the complex procedures involved in TCM, anthroposophic medicine, homeopathy and other CAM medical systems. These need substantial knowledge regarding the procedures in question and, as a consequence, a careful and thoughtful adaption of research methods. The available literature and ongoing discussions already offer seminal and stimulating contributions with respect to the most suitable available research methods [27], conceptual frameworks [28, 29] and experiences [30-32].

We recommend: The adequate use and careful adaption of quantitative research methods to answer research questions about CAM prevalence, safety, effectiveness and costeffectiveness.

\section{Qualitative Research in CAM}

Goal: Gaining a deeper understanding about the opportunities and challenges in CAM for consumers, providers and decision makers, and creating a comprehensive evidence base for CAM products and services.

Qualitative research methods are widely used in the field of social sciences, and they are increasingly acknowledged as vital to medical research. Qualitative research methods can increase knowledge about the perceived benefits or risks associated with CAM utilisation and provision, and often contribute a rich source of information complementing quantitative research.

There are a number of different fields in which qualitative methods are important in CAM research:

- Exploring the philosophical contexts of CAM therapies and systems;

- Investigating reasons and motives for utilisation or provision;

- Exploring CAM treatment experiences including the patient-provider relationship.

In addition, qualitative studies are crucial in informing quantitative research both when it comes to assessing the impact of the interventions and interpretation of quantitative outcomes. Qualitative approaches are also helpful in structuring the CAM research agenda and assisting in exploring the reasons for the heterogeneity of CAM regulation, financing, provision and utilisation in Europe. Qualitative methods are needed to broaden our knowledge base in CAM, particularly as we know too little about the multifaceted processes taking place in a CAM treatment.

There is evidence from some countries (e.g., UK, Germany, France and Switzerland) of what citizens value about and within CAM (see CAMbrella WP 3 report), but we still do not know exactly what they value in CAM treatments for their individual complaints/diseases. We need to build a solid base of understanding in order to design research that helps to fill the gaps in key outcomes of the overall treatment process. Qualitative research and theory-building are needed to generate valid hypotheses and to support CER, and must therefore be integrated into any research strategy. While it is clear to us that many published qualitative CAM research articles are a rich source of patient-centred information, they tend to be small and narrowly focused. Meta-ethnography is a very suitable method for summarising knowledge from different qualitative sources, and could help to create deeper insight into the conceptual models of CAM [33]. We consider that in addition to meta-analysis, meta-ethnography should also be part of the comprehensive evidence base for CAM.

Qualitative methods can help to build the necessary knowledge base, let us understand what happens in CAM treatments and what CAM practitioners understand they are doing. This helps us to understand the impact and patient perceptions of CAM. We fully support the increasing interest in combining qualitative and quantitative research methods to provide a comprehensive evidence base as well as the independent use of qualitative methods. The assessment of CAM treatments with qualitative studies is also very important to the preparation of clinical trials and to improve the study quality as well as 
the treatment process. It helps to inform the selection of outcome variables, to enable programme or process evaluation, to improve the researchers' reflective process and to clarify the implications of quantitative results.

We recommend: A stronger focus on qualitative research methods in order to provide syntheses and to explore the mechanisms and perceptions of CAM.

\section{Stakeholder Involvement}

Goal: Integration of all relevant perspectives and stakeholder interests in the research agenda.

There are a number of stakeholders with varying and different perspectives for whom CAM research is relevant. Among those are the European citizens as potential users of CAM, the various groups of medical and non-medical providers as well as policy makers and health care funders who define the conceptual and legislative context for CAM provision.

The integration of all these stakeholders' views in the process of planning and designing as well as performing research is vital. Citizens and providers may have different views on the outcomes they want to achieve with a specific CAM treatment. How a specific CAM modality or treatment is provided might vary significantly between different groups of providers. Obviously, the relevance and validity of CAM research depends to some extent on how these stakeholders' views are taken into account.

Given the diverse pictures of CAM in Europe, these needs and attitudes have to be integrated into any research programme in a structured manner. Qualitative methods, such as interviews and focus groups, as well as quantitative research methods, such as surveys, can be useful to assess the stakeholders' perspectives, ideas and interests. We believe that the quality and relevance of research will improve when stakeholders are integrated into the process of planning, conducting and interpreting research.

We recommend: Structured and transparent stakeholder involvement in all stages of CAM research is vital to ensure its relevance and validity.

\section{CAM Modalities in the Research Areas}

Goal: Research has to consider the possible contribution of CAM modalities to the EU health research priorities, therefore ensuring that the results are relevant for European citizens.

There is a wide range of different modalities within CAM. They all have different prevalence throughout Europe, heterogeneous evidence on efficacy and effectiveness as well as various levels of private and publically funded practice. Their theoretical and historical backgrounds are diverse as are their 'assumed' mechanisms of action. Definitions of CAM treatments are not uniform throughout Europe (see CAMbrella WP 1). Our information on prevalence of use and acceptance by European populations (see results from CAMbrella WP 3-5) is too poor to be able to suggest any useful ranking of modalities as there are likely to be national or regional differences in the relative importance of different CAM modalities.
Given this variability, a definitive EU-wide statement on which modalities should be primarily researched is impossible.

Our overall view is that CAM modalities we should first evaluate should be those most likely to contribute the health research priorities within the EU. Criteria for the selection of CAM modalities for future research have been proposed in the literature (see WP 7 review), such as the prevalence of use, expected impact on clinical practice and the overall feasibility of conducting productive research in a specific area. These priorities should be determined by a consensual process between the relevant stakeholders while taking into account the clinical and economic relevance of any research proposal.

We recommend: The choice of CAM modalities for which research is to be funded should be consensual and based on transparent criteria.

\section{Research Infrastructure}

Goal: Increase quality of CAM research by provision of optimal environments and a CAM research infrastructure in EU designed to foster collaboration and research excellence.

Good quality research which leads to thoughtful and informed health care decision-making is our main objective. Currently there is little research on CAM in Europe and no structure through which research can be coordinated within the EU. There is almost no significant investment in any EU country in a CAM research structure or strategy. This is in stark contrast to the large CAM research initiatives found in USA, Asia and Australia.

European CAM research suffers from

- a lack of knowledge about many of the CAM modalities, particularly if the research is carried out without the collaboration of CAM providers;

- poor collaboration with skilled conventional researchers and research structures;

- poor research methodology within CAM;

- limited and inadequate involvement of relevant stakeholders.

All these issues could and should be addressed by stakeholders, such as research funders. Investment in research capacity and structure is vital to enable good quality research. There is an urgent need for sufficient independent CAM research funding to

- build research networks in Europe with the aim of harmonising research nationally and internationally;

- attract experienced researchers to build research capacity in existing research groups that demonstrate metrics consistent with research excellence;

- offer fellowships at junior research levels to build intellectual capacity in high quality university departments committed to developing CAM research and collaborating with their conventional colleagues;

- develop structures that allow the dissemination of high quality reliable and trustworthy information about the evidence for and against CAM. 
This would enable the creation of a strong CAM research community establishing national and international research networks through the organisation and funding of annual meetings, conferences and research projects. Providing fellowships and scholarships in the field will create the leaders of tomorrow and would help to both connect and develop current European research capacity.

Collaboration with international experts and CAM organisations, such as the International Society of Complementary Medicine Research (ISCMR) and the NCCAM, would foster the development of excellence within an EU research infrastructure for CAM. Within CAMbrella, we favour opportunities to facilitate communication among European CAM researchers (see CAMbrella WP 8 report) and to link our research capabilities across Europe. In the past, no coordinated research strategies have been available within the EU. In order to deploy the framework of CAM research as outlined in this research roadmap and to achieve a relevant impact of CAM research on people's health care in the future, there needs to be a an institutional coordinated approach in research policy by the EU. We would suggest that as a first step, a European CAM research coordination office could be established that is dedicated to foster systematic communication between EU governments, public, charitable and industry funders as well as researchers, citizens and other stakeholders. The aim of this office would be to coordinate research strategy developments and research funding opportunities as well as to document and disseminate international research activities and their outcomes in particular clinical and epidemiological projects within the EU. This office would pursue a policy that is consistent with EU health creation policies and enable the development of CAM research through existing national and EU channels, such at the EU Framework Programme. This centre could also document and disseminate relevant EU and international CAM research projects. If this strategy is successful, then we suggest that this should develop into an EU-funded European Centre for CAM (ECCAM) comparable to the NCCAM in USA. The aim of such an European Centre for CAM would be to actively stimulate and support high quality research on CAM in the EU through an independent research strategy, aligned with EU health policy and its own capacity for project and fellowship funding.

We recommend: Improving the quality of CAM research by investing in education, training and collaboration of the CAM research community and by founding a European Centre for CAM (ECCAM) to stimulate high quality research in the EU.

\section{Conclusion}

CAM is popular in Europe and utilised by a significant proportion of EU citizens. Given the prevailing desire among citizens for self-empowerment in relation to their health and the increasing number of ageing patients with chronic disease and comorbidity, a further increase in CAM use seems probable. We know far too little about the safety and effectiveness of many CAM treatments, their mechanisms of action and their possible cost/benefit ratio in clinical practice. Our vision for 2020 is to begin the creation of a sustainable, broad, relevant and comprehensive knowledge base which will allow informed decisions for citizens, providers, funders and political stakeholders on whether, when and how CAM should or could be utilised.

We have identified several core research areas that need to be addressed urgently. Our current knowledge about which CAM modalities are used in Europe is incomplete. Europewide consensual definitions for CAM and data collection identifying the commonly used CAM modalities are urgently needed. Safety is a major issue. Unlike drugs, CAM modalities have evolved over time in practice and most have not undergone any safety evaluation prior to use. While CAM treatments may be safe, this needs to be properly investigated in order to protect European citizens.

We recommend the clinical evaluation of CAM from a realworld perspective and, where appropriate, within a framework of CER. We believe that research into the effectiveness of CAM treatments within a real-world setting is the key to the clinically economically effective use of CAM within EU health care systems. We also suggest research that identifies the underlying specific effects of CAM, but consider that effectiveness research should be prioritised. We recommend developing a mechanism that enables the utilisation of all available research methods, including qualitative research, to investigate the theoretical foundations of CAM and to systematically aggregate knowledge from different studies. Given the probability of strong meaning and context effects throughout medical practice, these should also be addressed.

Structural and sufficient financial support for research into CAM is urgently needed to develop the currently very limited research capacity. This could be achieved in the first step through the establishment of a European CAM coordinating research office and a time-limited grant to foster communication between EU governments, public, charitable and industry funders as well as researchers, citizens and other stakeholders. The aim of this office would be to develop a coordinated research strategy through existing research funding opportunities and to document and disseminate international research activities in this field. In the long run, a European Centre for CAM (ECCAM) should be established to further develop coordinated research strategy for CAM with the capacity to award independent research funding to foster high quality and robust research, with a focus on citizens' health needs and pan-European collaboration. This would establish a collaborative research investment in CAM ultimately informing stakeholders in the EU about CAM and its use within EU health care systems. Our task is to ensure that treatments are safe for patients and that the use of CAM in clinical situations is based on the best evidence available.

In order to consider whether CAM could be a part of the solution to the health care, health creation and self-care challenges we face by 2020 , it is vital to obtain a robust picture of 
CAM use and reliable information about its cost, safety and effectiveness in real-world settings. We need to consider how and in what ways CAM could be made available to European citizens. We need to engage in research excellence and utilise comparative effectiveness approaches, evidence syntheses and mixed methods to obtain this data. Our recommendations are both strategic and methodological. They are presented for the consideration of researchers and funders while being designed to answer the important and implicit questions posed by EU citizens currently using CAM. We propose an EU-funded European Centre for CAM (ECCAM) research to foster high quality robust research based on pan-European collaboration. We wish to establish a solid foundation for CAM research to adequately inform health care and health decision-making throughout the EU. A European research centre would support our vision of a common, strategic and scientifically rigorous approach to CAM research. We are confident that our recommendations will serve EU citizens.

\section{Acknowledgement}

We gratefully acknowledge the valuable advice of Wayne Jonas, Hugh MacPherson, Charlotte Paterson and Harald Walach, who participated as CAM research experts at the workshop in Castellaro, Italy, September 7-9th 2011. We would also like to thank all members of the CAMbrella project who took part in the consensus process (Franziska Baumhöfener, Meike Dlahoba, Gabriella Hegyi, Johanna Hök, Jesper Madsen, Frauke Musial, Nina Nissen, Stephanie Regenfelder, Paolo Roberti di Sarsina, Koldo Santos Rey, Monika Schagerl, Sorin Ursoniu, Jorge Vas and Solveig Wiesener) as well as all contributing members of the Advisory Board (Marion Caspers-Merk, Seamus Connolly, Martin Frei-Erb, Stephen Gordon, Nand de Herdt, Nora Laubstein, Walburg Maric-Oehler and Peter Zimmermann).

\section{Disclosure Statement}

The authors declare that they have no conflict of interests concerning this paper.

\section{References}

1 Eisenberg DM, Davis RB, Ettner SL, et al.: Trends in alternative medicine use in the United States, 1990-1997: results of a follow-up national survey. JAMA 1998;280:1569-1575.

2 Härtel U, Volger E: Use and acceptance of classical natural and alternative medicine in Germany findings of a representative population-based survey (article in German). Forsch Komplementarmed Klass Naturheilkd 2004;11:327-334.

3 Molassiotis A, Fernadez-Ortega P, Pud D, et al.: Use of complementary and alternative medicine in cancer patients: a European survey. Ann Oncol 2005; 16:655-663.

4 Bodeker G, Ong CK, Grundy C, Burford G, Shein K: WHO Global Atlas of Traditional, Complementary and Alternative Medicine: Text Volume. Kōbe, WHO, 2005.

5 Lewith GT: Funding for CAM. BMJ 2007;335:951.

6 Fischer HF, Junne F, Witt C, et al.: Key issues in clinical and epidemiological research in CAM - a systematic literature review. Forsch Komplementmed 2012;19(suppl 2):51-60.

7 Elm EV, Altman D, Egger M, et al.: The Strengthening the Reporting of Observational Studies in Epidemiology (STROBE) statement: guidelines for reporting observational studies. Ann Intern Med 2007;147:573-578.

8 Brien SB, Bishop FL, Riggs K, Stevenson D, Freire $\mathrm{V}$, Lewith G: Integrated medicine in the management of chronic illness: a qualitative study. Br J Gen Pract 2011;61:e89-96.

9 Institute of Medicine: What is comparative effectiveness research?; in Institute of Medicine (ed) Initial National Priorities for Comparative Effectiveness Research. Washington, D.C., The National Academies Press, 2009, p 29.

10 Last J, Spasoff R, Harris S: Dictionary of Epidemiology. Oxford, Oxford University Press, 2001.

11 Cardini F, Wade C, Regalia AL, et al.: Clinical research in traditional medicine: priorities and methods. Complement Ther Med 2006;14:282-287.

12 Fønnebø V, Grimsgaard S, Walach H, et al.: Researching complementary and alternative treatments - the gatekeepers are not at home. BMC Med Res Methodol 2007;7:7.
13 Tunis SR, Benner J, McClellan M: Comparative effectiveness research: policy context, methods development and research infrastructure. Stat Med 2010;29:1963-1976.

14 Mullins CD, Whicher D, Reese ES, Tunis S: Generating evidence for comparative effectiveness research using more pragmatic randomized controlled trials. Pharmacoeconomics 2010;28:969-976.

15 Zwarenstein M, Treweek S, Gagnier JJ, et al.: Improving the reporting of pragmatic trials: an extension of the CONSORT statement. BMJ 2008;337: a2390.

16 Hoffman A, Montgomery R, Aubry W, Tunis SR: How best to engage patients, doctors, and other stakeholders in designing comparative effectiveness studies. Health Aff (Millwood) 2010;29:18341841.

17 Linde K, Berner M, Kriston L: St John's wort for major depression. Cochrane Database Syst Rev 2008;8:CD000448.

18 Haake M, Muller H, Schade-Brittinger C, et al.: German Acupuncture Trials (GERAC) for chronic low back pain: randomized, multicenter, blinded, parallel-group trial with 3 groups. Arch Intern Med 2007;167:1892-1898.

19 Paterson C, Dieppe P: Characteristic and incidental (placebo) effects in complex interventions such as acupuncture. BMJ 2005:330:1202-1205.

20 Benedetti F: Placebo Effects. Understanding the Mechanisms in Health and Disease. Oxford, Oxford University Press, 2008.

21 Kaptchuk TJ, Miller FG: Viewpoint: what is the best and most ethical model for the relationship between mainstream and alternative medicine: opposition, integration, or pluralism? Acad Med 2005;80: 286-290.

22 Patient-centered Outcomes Research Institute (PCORI): Draft methodology report: our questions, our decisions: standards for patient-centered outcomes research. www.pcori.org/assets/Methodology Report-Comment.pdf (accessed 19.02.2014).

23 Pawson R, Greenhalgh T, Harvey G, Walshe K: Realist review - a new method of systematic review designed for complex policy interventions. J Health Serv Res Policy 2005;10(suppl 1):21-34.
24 Thomas K, Coleman: Use of complementary or alternative medicine in a general population in Great Britain. Results from the National Omnibus survey. J Public Health (Oxf) 2004;26:152-157.

25 Menniti-Ippolito F, Gargiulo L, Bologna E, Forcella E, Raschetti R: Use of unconventional medicine in Italy: a nation-wide survey. Eur J of Clin Pharmacol 2002;58:61-64.

26 Bücker B, Groenewold M, Schoefer Y, Schäfer: The use of complementary alternative medicine (CAM) in 1,001 German adults: results of a populationbased telephone survey. Gesundheitswesen 2008;70: e29-e36.

27 Craig P, Dieppe P, Macintyre S, Michie S, Nazareth I, Petticrew M: Developing and evaluating complex interventions: the new Medical Research Council guidance. BMJ 2008;337:979-983.

28 Polus B, Paterson C, van Rotterdam J, Vindigni D Embedding chiropractic in Indigenous Health Care Organisations: applying the normalisation process model. BMC Health Serv Res 2012;26:429.

29 Boon H, Verhoef M, O'Hara D, Findlay B: From parallel practice to integrative health care: a conceptual framework. BMC Health Serv Res 2004; $4: 15$

30 Sundberg T, Halpin J, Warenmark A, Falkenberg T: Towards a model for integrative medicine in Swedish primary care. BMC Health Serv Res 2007;7:107.

31 Sundberg T, Petzold M, Wändell P, Rydén A, Falkenberg T: Exploring integrative medicine for back and neck pain - a pragmatic randomised clinical pilot trial. BMC Complement Altern Med 2009:9:33.

32 Jong M, Busch M, van de Vijver L, Baars E: Towards a model for integrative medicine in the primary care of patients with chronic joint diseases and allergy (poster presentation). BMC Complement Alternat Med 2012;128(suppl):P342.

33 Smithson J, Britten N, Paterson C, Lewith G, Evans $\mathrm{M}$ : The experience of using complementary therapies after a diagnosis of cancer: a qualitative synthesis. Health 2012;16:19-39. 